\title{
A contribuição do estudo do colecionismo para historiografia do Museu Histórico do antigo "Oeste Paulista"
}

\author{
The contribution of the study of collectionism \\ to the Historical Museum historiography \\ of the former "West Paulista", Brazil
}

Silvia Maria do ESPÍRITO SANTO'

\section{Resumo}

Este artigo refere-se ao estudo do colecionismo público desenvolvido no período de 1930 a 1950, na região do Oeste Paulista, no Brasil. Considerado como um fenômeno social e objeto da ação colecionista, o colecionismo também é compreendido como ação seletiva originária da reunião de objetos. O termo colecionismo, do ponto de vista conceitual e da análise lexicográfica, permite estabelecer relações no âmbito da cultura material, face à articulação do eixo público/privado. O trabalho inclui a análise de uma personagem agenciadora, a partir de um exemplo específico e, ainda, verifica o processo de criação do museu de história natural e oficial, instituições tomadas como objeto, no contexto cultural. A pesquisa teve apoio da teoria deleuziana para a aplicação da metáfora do rizoma, na explicação das relações subjetivas, agenciamentos e estratégias.

Palavras-chave: Coleções de museu. Museu. História.

\begin{abstract}
This article refers to the study of public collectionism developed in the period from 1930 to 1950, in the region of West Paulista, Brazil. Considered as a social phenomenon and object of collectionist action, collectionism is also understood as the selective originary action of collecting objects. The term collectionism, in terms of conceptual and lexical analysis, allows us to establish relationships in material culture, given the articulation of a public/private axis. The work includes analysis of a character agency on the basis of a specific example, and also checks the process of creating an official natural history museum, institutions taken as an object, in the cultural context. The research was supported by the Deleuzian theory for the application of the metaphor of the rhizome, to explain the subjective relations, negotiations and strategies.
\end{abstract}

Keywords: Museum collections. Museums. History.

\section{Introdução}

O colecionismo do ponto de vista da relação entre uma pessoa e certos objetos pode ser compreendido 
humana. Também é considerado como uma das formas de reconhecimento e de interatividade do sujeito no mundo.

O presente estudo problematiza a ideia de colecionismo como fenômeno social, de incidência significativa no contexto cultural, porque se fez extensão do querer de um sujeito agenciador, que montou estratégias e condicionou objetos no espaço público, no período histórico do Estado Novo até os anos de desenvolvimentismo da década de 1950. Discute o contexto econômico e da cultura material, para a mediação na ciência da informação, que talvez guarde os aspectos do corpo material, os processos da historiografia e representação museológicas, do fenômeno do colecionismo, da documentação de objetos e dos documentos ali armazenados.

De uma maneira geral, compreende-se o colecionismo como coletar, reunir e compor acervos ou arranjar peças consideradas de cunho memorialistas, com traços fetichistas, com propriedades históricas e artísticas, num determinado espaço e tempo. Na esfera pública, baseado em princípios educativos, a tendência é considerar o colecionador como um guardião do passado em que a guarda de objetos "antigos" torna-se um "local" imaginário e onde se processam imagens de direito humano de apropriação universal.

Mais além dessa consideração, será instigante considerar que é com o colecionador que se encontram as questões profundas referentes ao campo do indivíduo e do coletivo, na construção da representação social. Frente à complexidade das ações colecionistas - inerentes ao desejo, à posse, ao poder, à negociação, associadas à ordem e ao arranjo nos lugares da organização dos objetos - são verificados elementos ocultáveis pelo ato de arranjar os objetos "antigos" e aproximar tais objetos da retórica do passado.

Os elementos aqui apresentados também são analisados no âmbito de áreas científicas a partir de proposições e argumentos fundamentados nas pesquisas da História, da Medicina, da Psicologia, da Antropologia, da Sociologia, na construção do conhecimento sobre coleções ou relacionadas ao fenômeno social - o colecionar.

Para o presente artigo, procurou-se adotar o colecionismo como objeto para dar sustentação ao argu- mento da importância do estudo da cultura, a partir de vertentes rizomáticas e das linhas de fuga implícitas na história social do colecionar e da influência do seu contexto cultural.

Plínio Travassos dos Santos, um agenciador da museologia, fundou os museus municipais da cidade de Ribeirão Preto, entre 1930 a 1950. Exerceu as funções de advogado, funcionário público, cronista, jornalista, historiador, e preocupava-se, especialmente, com a Educação. Ainda quando atuava como Diretor da Secretaria da Câmara Municipal, em 1937, foi designado a fazer inspeção escolar municipal e a partir de 1940 descreveu, de maneira sistemática, a importância da aproximação do ensino nos museus e na escola pública, em memoriais, cartas, listagens de aquisições, doações, compra, registros documentais em cópia carbono pertencentes ao acervo do Museu Histórico.

A discussão, aqui, também é referente à palavra e ao emprego do termo colecionismo para direcionar as designações no âmbito do contexto histórico e da sua representação nas mãos de um colecionador público. A pesquisa desenvolveu quatro níveis do estudo do colecionismo como a prática do colecionismo, a força do agenciamento, a apropriação dos objetos a partir de projetos institucionais interdisciplinares.

\section{Colecionar-colecionismo-collecting}

As explicações lexicográficas da língua portuguesa e da língua inglesa recebem conotações muito diferenciadas. Se para uma língua há significado originário do processo - collection - para a outra há outro sentido - produto/coleção - menos favorecido para compreender um processo ou ação individual ou coletiva.

Verifica-se que a língua portuguesa determina para o substantivo feminino primitivo coleção, derivado do latim (Ferreira, 2007), o sufixo nominal "ismo", para que o termo colecionismo receba o sentido conotativo de continuidade da ação e fenômeno. O gerúndio do verbo colecionar - "colecionando"-, adquire o sentido de continuidade do fazer. Como não é possível ser empregado como substantivo, "colecionando", se empregado no particípio - colecionado - entende-se como "coisa em si", como finalização de um processo iniciado do ato de colecionar. 
Coleção, verbete de dicionário, é descrito na língua inglesa da seguinte forma: Collection, the act or process of collecting, something collected; esp: an accumulation of objects gathered for study, comparison, or exhibition [...] (Websters, 1976).

Para definir o que é uma coleção identificam-se os aspectos situacionais dos significados do termo na frase. A partir da precisão semântica do termo inglês collection, verifica-se o sentido conotativo da palavra collection -, cuja compreensão torna-se limitada ou prejudicada na tradução para o português.

No caso da língua inglesa, efetiva-se a compreensão como um processo, um aprendizado. A "coisa coletada" (something collected), no sentido do ato consumado, e o fazer da coleção (collection) aproximam-se e assemelham-se - collection/colecionismo - nos sentidos semânticos utilizados para identificar o objeto (real), e o objeto apropriado pelo sujeito converte o significado da ação em movimento.

Colecionismo no português, de forma substantiva, poderá expressar o desenho da escala produtiva social, isto é, daquilo que poderá ser produzido coletivamente. Ao significar as características da ação de quem coleciona, colecionismo fora sustentado pelo termo coleção, que é carregado dos significados das ações colecionistas, as quais permitem indicar situações e movimentos invisíveis no ato de colecionar.

Estas que são derivadas do verbo colecionar, se aferidas pelo ângulo do estudo das subjetividades, percebe-se que são geradas a partir de desejos, das intenções individuais ou coletivas, manifestas no tempo e no espaço.

Na literatura especializada de áreas diversas verificam-se os sentidos do colecionar além do que seja arranjo ou acúmulo. Além das significações aparentes, podem carregar significados de uma prática que consiste na reunião de coisas projetadas a partir das semelhanças e dos elementos significantes.

Por via das diversas narrativas do ponto de vista da história, da cultura e da arte, a partir do estudo das trajetórias das coleções das Bibliotecas, dos Gabinetes de
Curiosidades, dos Museus são possíveis as identidades colecionistas que, através de formas estranhas à sua criação originária, permitam que tais objetos colecionados passem também por uma (re)significação determinada pela posse.

Os "locais" de condensamento, figurados em nós rizomáticos de conteúdos culturais no espaço, passíveis de transmissão nas instituições de guarda e onde permanecem os objetos considerados partes de uma coleção pública, estão também sujeitos a adquirir significações específicas, dependendo da função que a instituição reclama deles. Desta forma, a metáfora do rizoma se completa nas vertentes expansionistas do local iniciado.

O processo de descontextualização que sofre o objeto também o desfigura e são percebidas as modalidades do objeto em diversos museus com caráter social, fluxos e dinâmicas de acesso diferenciados, a partir das relações sociais provocadas pelos objetos e das apropriações do sujeito em determinado contexto em que é praticado o colecionismo.

\section{Agenciamentos, territórios e receptores}

No sentido da análise, agenciamento e colecionismo, são traçados, como linhas de fuga, desenhos cartográficos (ou rizomas²) do campo social. É justamente no campo social que as estratégias são criadas.

Embora exista uma expectativa no papel transformador dos agenciamentos enquanto força de causa, Deleuze e Guattari (1995) afirma que as linhas de fuga nem sempre são revolucionárias. Na verdade, muitas vezes são alvos dos dispositivos do poder (Foucault, 1996), ou da "onipresença 'invisível' das práticas disciplinares" (Wellausen, 2006/2007). Retomam-se os dispositivos do poder como extensões ou micropontos da ideologia que, sempre institucional, subtrai do sujeito o sentido de coletividade. O traçado da linha de fuga para a formação das instituições acompanha o trajeto percorrido, a partir da força do desejo, na luta contra a dispersão das significações, como o exemplo da pesquisa em desenvolvimento, no contexto do café.

\footnotetext{
$\overline{2}$ Encontra-se o termo rizoma apropriado da Biologia e aplicado como metáfora, do sentido de figuração para auxiliar na compreensão daquilo que não tem raiz, mas, sim, possui pontos de expansão e recriação.
} 


\section{Museus revelam-se como estratégia da sociedade: Rizomas e museus, linhas de fuga e desterritorização}

Neste trabalho, torna-se relevante o debate entre Deleuze e Foucault (Rolnik; Pelbart, 1996), com a preocupação de Deleuze orientada no sentido de que as linhas de fugas são determinações primeiras, que vêm antes das estratégias. Os museus revelam-se como estratégia da sociedade que, em contextos culturais diferenciados no tempo, produzem rizomas informacionais. Esses só aparecem no momento posterior, direcionados para o agenciamento e para a ação realizada. A intenção do agenciador, combinada com os seus próprios desejos, decide, seleciona e classifica os objetos apropriados dos contextos culturais: ele procura dominar a desterritorialização traçando linhas rizomáticas.

Durante o Renascimento, os colecionadores figuraram como personagens centrados em interesses obscuros, nobres, econômicos e artísticos ou apenas assumiam sintomas de caprichos e vaidades. A Revolução Francesa preocupou-se com o sentido social da educação; entretanto apenas no Moderno os museus inseriram-se no planejamento social, com o papel de produtores de conhecimento.

Por esta vertente, indica-se que o museu não seria concebido como um apanágio das proposições da museologia contemporânea, que prega ser o espaço museal o local onde se realiza a "reconstrução" da memória dos fatos e dos processos sociais perdidos. Nem mesmo é nos museus em que se configuram os fenômenos de resistências sociais para que as sociedades possam revigorar-se de "algo" perdido no passado. Pode-se afirmar que, neles, resume-se a possibilidade de compreender um estado crítico da continuidade das tradições e valores, entre a fronteira da presença e da ausência, e se situa a interpretação das narrativas diversas e as maneiras próprias e impróprias de colocar, classificar e preservar o mundo. Tais museus são as "linhas objetivas que atravessam a sociedade" e esse processo representa o fim da intenção individual e o início da circularidade informacional.

Para autores filiados à filosofia francesa pós-marxista, Deleuze, Guattari e Foucault, e citados neste texto, não se explica o aparecimento das instituições apenas pela extensão ideológica da ação do poder de determinada classe. Considera-se que o Estado, como na visão de Foucault, organiza-se em formas heterogêneas, múltiplas e em microdispositivos. Outro direcionamento dessa concepção é a de que instituições são pontos de dispositivos de poder.

Deleuze, antes de ser identificado como teórico no campo da psiquiatria, é pensador e filósofo, que contribuiu para reflexões além dos conceitos baseados na relação objeto-sujeito. Seguindo o autor, quando é retomada a categoria da tese sobre os dispositivos, conclui-se que eles não se sustentam na explicação do problema que se coloca para Foucault. O pensador pós-1968 compreende que ao prazer não se imprime um valor positivo, porque ele interrompe o processo de desejo. Todavia, os dispositivos de poderes serão produzidos pelos agenciamentos do desejo. O desejo é sempre combinado a um agenciamento e implica sempre um corpo sem órgãos, que se define em "zonas de intensidade, de limiares, de gradientes, de fluxos" (Deleuze, 1993, p.21).

Na posição deleuziana, o poder é uma afecção do desejo, o que possibilita a compreensão de que o agenciamento do desejo é o provocador das formações de poder.

\section{Rizoma cultural gerado para o futuro}

Para compreender o papel da representação baseadas na linguagem natural das coleções sobre o período cafeeiro, será convincente adotar perspectivas de investigação como as inferidas por Deleuze e Guattari (1995), na construção do conceito de rizoma para se compreender os agenciamentos "plantados" no desejo.

A proposta, para que sejam atingidos os objetivos desse artigo, descarta os caminhos da descrição unitária do objeto, embora os últimos autores considerem que as classificações, como tentativas de domínio do passado, datadas no tempo e no espaço, tornaram-se borrões das linhas de fuga dos agenciamentos tardios, representados nestes museus históricos.

Midas surpreendia a realidade dos homens, ao transformar os objetos do mundo material em ouro, através do seu poder. Ao colecionador, haveria, na presença dos objetos, um projeto acabado da memória, subvertido 
pela ausência permanente, à realidade museal presente. Não há raízes, nessa tradição, de classificações, porque a história não se refaz no passado, mas se dá oportunidade, no presente, de construí-la. Na verdade, há pontos ou rizomas interconectados, em desenhos cartográficos, ligados por laços políticos, econômicos e sociais, ao desejo de representar o passado.

A partir dos estudos contemporâneos de análise do papel social e funcional dos museus, se verificam que, a eles e às coleções, caberia a missão de subsidiar a ideia de passado materializado, a partir dos instrumentos de pesquisa, dos métodos de classificações ou de montagens de cenários, a fim de que todos pudessem, democraticamente, recuperar a memória. Contudo, acredita-se que a redundância temática da transferência da linguagem natural para contextos históricos poderá ser evitada na investigação do colecionismo, do desejo e agenciamentos.

A formação das coleções deverá ser analisada para que elas não sejam apenas suportadas pelos códigos linguísticos puramente descritivos, ou por substituições, pouco refletidas ou até mesmo compulsivas, de caracteres tecnológicos. Os processos do agenciamento, restituídos a partir da documentação das práticas museológicas, na busca de respostas verdadeiras para antigas questões, aparecem como micropontos das intenções ou desejos, em que o colecionismo, subalterno ao pretendido, é agenciado em tempos diferentes. Inicia-se, portanto, o projeto de expansão do rizoma.

\section{Cultura material entre o público e o privado no colecionismo}

O destaque do colecionismo público no texto não está apenas na ação humana, mas frente à cultura material. Estão também presentes as relações sociais no tempo e no espaço determinado pela pesquisa. Esta, como já mencionado, considerou o processo do colecionismo no aspecto público e como fenômeno da sociedade.

A pesquisa apontou o contexto cultural da cidade de Ribeirão Preto, na história da produção do café e nas relações sociais no Brasil. Particularmente, o período em questão refere-se à segunda fase de produção econômica e de desenvolvimento no Oeste Paulista, no estado de São
Paulo. Ainda, a pesquisa baseou-se na identificação das ações colecionistas e documentalistas do sujeito da ação na atividade colecionar.

Da época em que não se vive mais - do passado -, o legado"herança"no presente é a fonte documental revista a partir da observação dos resultados dos atos de quem praticou o colecionismo e, neste caso, a organização de um museu.

Afeições são etéreas e, por isso, através do olhar pretérito, os objetos apropriados do passado podem ser registráveis somente quando há uma intenção e um suporte físico. Ao pesquisador cabe somar, discernir e descrever os significados ou valores a eles atribuídos na sociedade moderna. Mesmo assim, não será possível determinar ou dominar de forma absoluta as relações sociais, frente às maneiras pelas quais tais objetos foram aprisionados, identificados, apropriados e submetidos à circulação da informação no "espaço museal".

De qualquer perspectiva, negando ou não a sua apropriação, a circulação e a quantidade deles inferem questões da proveniência, da autoria, da função, da forma, do conteúdo informacional para propiciar aos objetos um lugar dos sentidos atribuídos, nas qualidades interativas e potenciais dessa ação coletora e colecionadora.

Para efeito comparativo, permitiu-se representar um "lugar"no imaginário figurativo do passado, na função da caracterização dos atos apropriativos do colecionador. Nessa permissão, deve-se atuar com a possibilidade da reconstituição narrativa de valores de grandeza, justiça e igualdade, próprios da estética e da ética; do bom gosto, das crenças, das tradições e da "alma do povo", e também próprios de cada contexto social.

Embora sejam consideráveis as incertezas econômicas, históricas e sociais, tais como aquelas que são decorrentes do sistema de produção - conflitos de classe, detenção dos bens de produção na hegemonia do poder, substituição acelerada da tecnologia -, delas também resulta a sua (auto)representação museológica.

As inúmeras tentativas do ato de colecionar poderão ocorrer e caracterizar o fazer, os comportamentos, os hábitos, as atitudes repetidas, as manias, as perturbações no sujeito da ação, de caráter privado ou público. Essas ações poderão possuir características de determinadas inferências, como históricas, filosóficas, sociológicas, 
psicológicas ou estéticas no processo investigativo do pesquisador e nos atos derivados dos verbos colecionar e documentar.

Walter Benjamin (1892-1940), filósofo reconhecido como um dos mais notáveis intelectuais alemães, em Obras das Passagens (Benjamin, 1999, p.12), aplica os conceitos coleção/colecionismo, abordados e compreendidos como o objeto no museu e na "organicidade" da coleção, onde foram desprendidos de suas funções do contexto de pertencimento original. A nova relação com o presente se faz com associações estreitas com o seu semelhante, isto é, o objeto que compõe a mesma coleção insere-se na categoria complementar - completude não satisfeita - ao quebrar sua mera existência na cadeia produtiva econômica e ao dotar-se de uma aura no espaço museal.

Para exemplificar esse processo, tomamos qualquer objeto que teve a sua origem na escala industrial e, depois de funcionar no tempo e no espaço, rompeu definitivamente com o uso original. O destino inicial determinado pela fabricação, como o de circular no mercado, depois ser apropriado e consumido, agora foi substituído (Forty, 2007) pela função de documentar e passar a integrar uma coleção, privada ou pública. Neste sentido, o colecionismo foi entendido como resultado das ações de desejos vigorosos, intermitentes ou pouco contínuos no tempo e no território físico.

O colecionismo, estudo explorado como fenômeno da subjetividade ou como ação social, foi desenvolvido por Blom (2003), que tomou as origens e as vertentes dos sentidos expostos da paixão, das proposições da narração, da verdade alquímica até serem representadas pelas linguagens das classificações e dos métodos científicos.

A funcionalidade dos objetos, a partir do estudo comparativo da produção em diferentes momentos econômicos e sociais, interfere na produção sempre modificada na ordem do uso social e no advento de novas tecnologias que os substituíram em diferentes usos: doméstico, científico, administrativo, memorial, artístico ou religioso. formas e ordens que tomaram tais coleções, particularmente no Museu Histórico e de Ordem Geral Plínio Travassos dos Santos.

\section{O objeto museológico e a ação colecionista pública}

A partir das etapas da pesquisa, que priorizou o conceito de suporte de informação ou fonte de informação, foram entendidas (informação e fonte) como o resultado de busca de sentido fora do objeto, isto é, dos aspectos históricos e sociais dos próprios objetos e as relações sociais por eles provocadas.

O objeto, isolado de suas funções originais, ao longo de uma trajetória espacial e temporal, foi retirado de circulação da produção e, submetido ao olhar do avaliador, do colecionador; passa para um estágio de (re)significação. O ingresso de um novo objeto, ou vários, numa determinada coleção, e com significados atribuídos pelo colecionador, significa também uma mudança de uma fase ocupada pelo objeto no tempo e no espaço de uso para um lugar de expansão de informações.

Alguns critérios foram adotados pelo colecionador, quanto à avaliação da forma do objeto, à sua capacidade de reter, presenciar ou postergar no tempo, e com precisão, o seu conteúdo informacional ou, ainda, poder ter sido selecionado a partir do critério estritamente afetivo. Os objetos foram classificados em diversas classes e atribuições - como históricos, artísticos, científicos ou fetichizados - antes de serem inseridos na instituição coletora que será aqui analisada: o museu histórico no interior do estado de São Paulo.

Nesse momento, para quem analisa coleções, e reconstituindo-se a trajetória dos objetos ou das coleções, da proveniência ou autoria, percebe-se que eles pertencerão a outro senhor. Agora, o tutor será invisível e social, com intenções de disponibilizá-lo (ou não) ao olhar alheio. Nesse arranjo, a institucionalização da coleção serve para que, além das significações outorgadas pelo colecionador, outras novas possam ainda ser criadas. De maneira estreita com o seu semelhante, isto é, com "afinidades" sígnicas com um outro objeto de uma mesma coleção, compõe uma narrativa própria de uma maneira de ver o mundo a partir do entusiasmo do desenvolvimento. 
Assim, o que é objeto museológico? Sem confundir com os sentidos semânticos do objeto da Museologia, o objeto museológico (que é o artefato) poderá significar o contexto econômico e social. Rússio ${ }^{3}$, já em uma publicação de 1984, "Produzindo o passado", advertia que:

[...] para o museólogo, cultura é, essencialmente, fazer e viver, ou seja, cultura é resultado do trabalho do homem, seja ele um trabalho intelectual, seja ele um trabalho intelectual refletido materialmente na construção concreta. Daí, vem a relação-objeto, homem-objeto-realidade. A paisagem, o meio natural percebido pelo homem é um objeto percebido pelo homem enquanto é alguma coisa fora dele. A palavra objeto já traz essa carga: "objeto", ou seja, que existe além de, fora de, apreendido pela consciência do homem. A paisagem percebida pelo homem é para o museólogo também um dado cultural (Arantes, 1984, p.61).

“Em outras palavras, faz-se necessário considerar o artefato nos diversos aspectos dos ciclos de produção, distribuição e consumo" (Meneses, 1983, p. 9).

Entende-se que o artefato, composto de dimensões bidimensionais ou tridimensionais, é produto da teoria e da prática. Com o conceito cultura material, além de poder evidenciar simbologias ou ideologias trazidas pela capacidade interpretativa de qualquer um dos seus componentes (manufaturado ou industrializado), é algo perturbador, eminente e proveniente das relações sociais, como vetores indicativos das percepções menos aguçadas ou das propriedades menos evidentes de um objeto.

Para Baudrillard (2002), através da Enciclopédia de Diderot, foi possível inventariar e classificar exaustivamente o mundo ao redor do homem; contudo, o desenvolvimento tecnológico criou objetos e estabeleceu uma enormidade de graus para as classificações equivalentes à diversidade dos objetos, neste mundo em que se misturou o natural e o artificial.

Na sociedade, todo objeto transforma alguma coisa em outra, embora se pergunte: em qual sistema cultural é fundada a continuidade de significações e funções desses objetos?

O estudo desse sistema "falado" dos objetos vale dizer, do sistema de significações mais ou menos coerente que instauram, supõe sempre um plano distinto desse mesmo sistema "falado", mais rigorosamente estruturado do que ele, um plano estrutural, além mesmo da descrição funcional: o plano tecnológico (Baudrillard, 2002, p.11).

A partir da constatação da perda das atribuições físicas e funcionais do objeto, a compreensão do valor do tempo em que ocorrem os objetos produzidos, consumidos, possuídos, personalizados ou descartados, define o objeto museológico. Para evitar o risco do esquecimento funcional do esquecimento programado, é necessário conhecer o objeto inserido num plano de racionalidade, num ambiente museológico.

Uma das perspectivas de investigação do processo museológico é desenvolvê-la com base no uso ampliado do acervo museal. Em primeira instância, conhecer os percursos dos objetos representados ou expostos, reconhecendo as suas biografias ${ }^{4}$. Como esclarece Meneses (1998), dar lugar às possibilidades criativas das diversas significações, sem com isso anular a importância das classes e termos adotados, numa segunda instância, para o arranjo dos acervos e, finalmente, para a exposição.

O que se busca aqui é associar, em princípio, o papel da mediação da informação registrada com o estudo de uma coleção de objetos no interior do museu histórico, demarcada pela sua função testemunhal do tempo operante e pela construção da memória social, caracterizando o período moderno: objetos com legendas explicativas, ordenação linear e monitoria (guia), com a função de "explanar corretamente" sobre determinado assunto. São tarefas exaustivas e tornam-se complexas demais quando não há entusiasmo, crítica e planejamento para discernir os conteúdos informacionais de interesse.

Contudo, a atuação de Santos na administração, no planejamento e na elaboração de propostas para

3 Waldisia Rússio, crítica da formação da profissão de museólogo no País, foi coordenadora do curso de Museologia (Pós-Graduação) da Fundação Escola de Sociologia e Política de São Paulo e implantou o projeto "Museu da Indústria", da Secretaria da Indústria e do Comércio, entre outros projetos pioneiros, na concepção dos anos de 1980.

4 O Museu da Inconfidência de Ouro Preto, dirigido pelo Governo Federal, foi remodelado com linguagem contemporânea de museografia. Recorre-se a este exemplo, verificado em excursão didática proporcionada pelo curso Ciência da Informação e da Documentação da FFCLRP-USP, para demonstrar a realização de esforços no sentido de qualificar a informação no seu ambiente. 
compor coleções, definiu-se, por isso, no âmbito do modo de colecionar, agenciar e circular, objetivando dar acesso à informação, a respeito da representação museológica do período cafeeiro paulista.

\section{Considerações Finais}

Frente ao quadro de destaque do problema da investigação a respeito do colecionismo público, no "Oeste Paulista", surgem quatro níveis para compreender o colecionismo no panorama da historiografia museológica, o agenciamento e a circulação das informações dos objetos que se situam entre a complexidade temática e o uso, entre a análise documental e o domínio dos processos de investigação.

O primeiro nível é aquele que advém da prática do colecionismo pela força do agenciamento, da apropriação dos objetos que objetivam a formação das coleções no tempo e no espaço. Os objetos semióforos, dotados de significados, quando são expostos ao olhar, não sofrem usura física (Pomian, 1984); entretanto, a sua condição em criar relações metafóricas entre pessoas e o mundo, necessariamente, não resulta em garantias de continuidade da tradição, da transmissão de valores ou da sua (re)significação. Talvez o maior equívoco do colecionismo seja tomar como ponto de partida, e disparar no mundo presente, os arremedos (muitas vezes lamentáveis tentativas) de reconstituição do passado, do enunciado da permanência, da conservação e de teatralizar narrativas dos valores de contextos históricos.

O indivíduo colecionista, na qualidade de agenciador, objetiva racionalizar as ações, infere suas concepções, valores e práticas a partir das questões sociais evidentes no processo de colecionar. A interligação entre o indivíduo e tais questões, aqui levantadas no sentido que possa existir além da reunião dos objetos do colecionismo, também se relaciona em estruturas psíquicas, baseadas em padrões éticos ou estéticos, acompanhando as interações anteriores de seus genitores (Formanek, 1994), ainda que, na dinâmica social, valores influenciem e sejam influenciados.

Por exemplo, no contato com a documentação museológica, nos registros, a leitura dos documentos de acervos museológicos permitida por alguma razão, isto é, impressos, manuscritos ou virtuais, empregam termos em campos descritivos dos objetos: aquisição por compra, por doação e por receptação; esta última, comum em antiquários.

Os termos "compra" ou "doação", condição das aquisições descritas nos formulários e catálogos, são genéricos demais para o aprofundamento das razões do agenciamento do colecionador. Tais termos ocultam as relações sociais estabelecidas a partir de interesses de aquisição ou de descarte de objetos ou mesmo de coleções.

O segundo nível é aquele no qual os objetos são (re)interpretados através da linguagem natural de uma sociedade. Ao submeterem tais órfãos ao novo batizado e destinar-lhes novas denominações espaciais, temporais e classificações, também Ihes são impostos novos curadores e pertencerão a novos períodos, nem sempre satisfatórios do ponto de vista da conservação e da acessibilidade.

O terceiro está relacionado à cultura a que pertencem no processo de contextualizar os modos do fazer no espaço (Certeau et al., 1994). O conceito lugar é um elemento-chave para o entendimento das bibliotecas, arquivos, museus e centros de memória, porém pouco discutido nessas áreas. A questão dos contextos e das ambiências dessas instituições poderá ser incorporada e ampliada dentro de uma discussão sobre o lugar. Isto é, a institucionalização de práticas profissionais e sociais ligadas à memória e ao conhecimento deveria ser interpretada pelo reconhecimento da construção social desses lugares e das determinações posteriores que eles exercem nas instituições mencionadas.

As relações assimétricas entre os homens e o culto ao passado (dos homens, das tradições morais e éticas) são acentuadas no sistema de força das autoridades institucionais. Vista por este ângulo, a função da tradição fica mais clara, porque está sob a luz da dependência do passado conscientemente criado. Embora a cultura material seja uma ferramenta, o campo das tradições, na maioria das vezes, aparece como tentativa de eliminar possíveis diferenças e homogeneizar mudanças sociais.

Sociedades que se autorrepresentam nem sempre representam de fato a sua imagem espelhada nas contradições das relações sociais. São necessárias as forças da memória representadas na imagem "inventada", caleidoscópica, construída e aceita socialmente, as quais passa- 
ram a ter um papel gerenciador dos vínculos sociais, ou dos elementos da máquina do poder para permitir a sua reprodução (a memória convertida em história oficial).

A simples descrição do objeto está sujeita aos significados mais complexos e às ambiguidades da linguagem adotada. As formas de relação do homem com "as coisas" e da sua própria simbologia construída variam ao longo do tempo. Os sentidos atribuídos aos objetos são atrelados às maneiras da recepção e não se reproduzem naturalmente como valores, porque estão condicionados às atribuições da linguagem, da produção, da circulação, das formas da reciclagem, do consumo próprio do seu tempo e espaço social.

Paradoxalmente, as apropriações dos objetos pela memória não passam necessariamente por esses caminhos. A apropriação dos objetos pela memória pode ser direta, evocativa, emocional e sem mediação de linguagem.

\section{Referências}

ARANTES, A.A. Produzindo o passado. São Paulo: Brasiliense, 1984.

BAUDRILLARD, J. O sistema dos objetos. São Paulo: Perspectiva, 2002.

BENJAMIN, W. Obra das passagens, 1927-40, trechos selecionados. In: SCHOLZ, L.A. Noite do colecionar. Bonn: InterNaciotiones, 1999.

BLOM, P. Ter e manter. Rio de Janeiro: Record, 2003.

CERTEAU, M.; GIARD, L; MAYOL, P. A invenção do cotidiano. Petrópolis: Vozes, 1994. v. 1-2.

DELEUZE, G. Desejo e prazer. Cadernos de Subjetividade, v.1, n.1, p.15-25, 1993.

DELEUZE, G.; GUATTARI, F. Mil platôs: capitalismo e esquizofrenia. São Paulo: Ed. 34, 1995. v.2.

FERREIRA, A.B.H. Novo dicionário Aurélio da língua portuguesa. Curitiba: Positivo, 2007.

FORMANEK, R. Why they collect: collectors reavel their motivations. In: PEARCE, S. (Org.). Interpreting objects collections. London: Routledge, Taylor \& Francis, 1994.
A vertente do universo da cultura material, na definição de bens culturais, em que também ocupam lugar as coleções museológicas, irá nortear e compor o patrimônio cultural social ou universal. No âmbito da organização social, esse modo de pensar demonstrará outras e novas perspectivas quando se propuser a investigar os objetos museológicos associados à memória social.

Estes componentes - intenção, articulação, circulação - do colecionismo não pertencem mais ao passado, mas a um processo colecionista, possuídos de características profundamente particulares aos olhos do julgamento acadêmico e social. Remontam-se as suas histórias e, por força da construção da memória, podem constituir um quadro referencial dos aspectos das relações sociais particularizadas nessas coleções que buscam representar o período cafeeiro no antigo Oeste Paulista.
FORTY, A. Objetos de desejo: design e sociedade desde 1750. São Paulo: Cosac Naify, 2007.

FOUCAULT, M. Vigiar e punir: nascimento da prisão. 29. ed. Petrópolis, Vozes, 1996. p.125-52.

MENESES, U.T.B. A cultura material no estudo das sociedades antigas. Revista de História, n.115, p.103-117, 1983.

MENESES, U.T.B. Memória e cultura material: documentos pessoais no espaço público. Estudos Históricos, n.21, p.1-20, 1998. Disponível em: <http://virtualbib.fgv.br/ojs/index. php/ reh/article/view File/2067/1206>. Acesso em: 14 mar. 2011.

POMIAN, K. Coleção. In: ENCICLOPÉDIA Einaudi. Lisboa: Imprensa Nacional, 1984. v.1, p.51-86.

ROLNIK, S.; PELBART, P.P. (Org.). Gillles Deuze: especial nos cadernos de subjetividade. São Paulo: Pontifícia Universidade Católica de São Paulo, 1996.

WELLAUSEN, S. S. Os dispositivos de poder e o corpo em vigiar e punir. Revista Aulas: Dossiê Foucault, n.3, p.1-23, 2006/2007.

WEBSTERS' new collegiate dictionary. Springfield: G\&C Merriam, 1976. 